\title{
Bacteroides fragilis is a silent pathogen in acute appendicitis
}

\author{
K. M. ELHAG, M. H. ALWAN*, M. S. AL-ADNANIt and R. A. SHERIF*
}

Departments of Microbiology and TPathology, Faculty of Medicine, Kuwait University and "Department of Surgery, Sabah Hospital, Kuwait

\begin{abstract}
Summary. The role of Bacteroides fragilis in the pathogenesis of acute appendicitis was studied in 135 patients in four patient groups: normal (17); phlegmonous appendicitis (17); gangrenous appendicitis (75); and septic complications of appendicitis (26). Aerobic and anaerobic bacteria were isolated from all groups and members of the ' $B$. fragilis group' were the most common anaerobic isolates. The rate of isolation of $B$. fragilis was similar from normal and inflamed appendices but was significantly higher from those with septic complications $(\mathrm{p}<0.01)$. Antibodies against $\boldsymbol{B}$. fragilis were demonstrated in patients of all groups and occurred with similar frequencies in patients with normal and inflamed appendices but at a significantly higher rate in those with septic complications $(\mathrm{p}<0.01)$. Whereas patients in this latter group showed IgMantibody responses to $B$. fragilis only, those with acute appendicitis had IgM antibodies against a wide range of organisms of the ' $B$. fragilis group' which suggests that $B$. fragilis does not play a significant role in acute appendicitis but may be a major cause of its septic complications.
\end{abstract}

\section{Introduction}

Acute appendicitis is a common condition often requiring surgical intervention to prevent complications. However, the aetiology of this condition is obscure and various possible aetiological factors have been reported. Obstruction has been suggested as a major predisposing factor (Shackleford and Zuidema, 1981) whereas the studies of Burkitt (1971) showed a direct relationship between the incidence of appendicitis and the amount of refined carbohydrate in the diet.

Since the infective aetiology of appendicitis was first proposed by Veillon and Zuber (1898), several reports showing the importance of anaerobes, and in particular of Bacteroides fragilis, in the pathogenesis of appendicitis have been published (Werner $e t$ al., 1975; Lari et al., 1976; Pieper et al., 1979 and 1982). In confirming the infective aetiology of appendicitis, Pieper et al. (1982) demonstrated rising titres of $B$. fragilis antibodies in sera from patients with acute appendicitis and showed, furthermore, that the immune response of these patients increased with the degree of appendix destruction and the duration of the inflammatory process. In most of the above studies, however, control groups of patients with normal appendices were not included. Although the role of $B$. fragilis in the

Received 15 Mar. 1985; revised version accepted 26 Jun. 1985. pathogenesis of appendicitis is still uncertain, its significance in septic complications of appendicitis is well established (Andersen et al., 1972; Leigh et al., 1974; Willis et al., 1976).

The objectives of this study were to determine the types of bacteria present in normal and inflamed appendices as well as in appendix-related infections, and to evaluate the immune response to $B$. fragilis of patients with these conditions. This comparative study should shed more light on the role of $B$. fragilis in the pathogenesis of acute appendicitis.

\section{Material and methods}

\section{Patients}

One-hundred and thirty-five patients admitted to Surgical Unit D at Sabah Hospital for appendicectomy between Oct. 1983 and Jan. 1985 were included in the study. There were 108 male and 27 female patients, aged from 12 to 55 years and of mean age 27 years. The patients were grouped according to histopathological and clinical findings. In patients of: group 1 (normal appendix) appendices showed no evidence of acute inflammation; group 2 (phlegmonous appendicitis) there was acute suppuration and inflammation involving only the appendicular mucosa and submucosa; group 3 (gangrenous appendicitis) there was diffuse suppurative inflammation involving the whole thickness of the appendicular wall; group 4 (septic complications) there were appendixrelated infections such as peritonitis, appendicular abscess and post-appendicectomy wound-infections. 


\section{Microbiological methods}

Appendices after removal were opened longitudinally and the contents placed in anaerobic transport media (Portagerm, bio Mérieux, Charbonniérs-Les-Bains, France) and sent to the laboratory within $24 \mathrm{~h}$. Specimens of pus collected from infected sites of patients with appendix-related infections were also sent in anaerobic transport media. All culture procedures were performed in an anaerobic system (Model 1028, Forma Scientific, Marietta, OH, USA) in an atmosphere of $\mathrm{N}_{2} 90 \%, \mathrm{H}_{2} 5 \%$ and $\mathrm{CO}_{2} 5 \% \mathrm{v} / \mathrm{v}$. Specimens were inoculated on to Blood Agar (CM55, Oxoid), Schaedler Blood Agar (CM437, Oxoid) with Kanamycin-Vancomycin mixture (55681, bio Mérieux) and Schaedler Blood Agar with gentamicin $80 \mu \mathrm{g} / \mathrm{ml}$, and intu Brain Heart Infusion (BHI) Broth (CM225, Oxoid). Cultures were examined after anaerobic incubation for $48 \mathrm{~h}$. BHI-broth enrichments were subcultured on to the same three solid media. Specimens were also inoculated on to plates of blood agar and MacConkey Agar (CM7, Oxoid) for aerobic incubation for $24 \mathrm{~h}$.

Colonies (5-10) were selected from each plate and identified -aerobic bacteria by standard microbiological techniques (Isenberg et al., 1980) and anaerobic bacteria biochemically by the Anaerobe Tek System (Flow Laboratories Inc., McLean, VA USA) and by their end products of glucose metabolism as determined by gasliquid chromatography (Shimatzu Gas Chromatograph GC-9A, Shimatzu Corp., Kyoto, Japan). The strains were definitively identified according to Holdeman et al. (1977).

\section{Serological methods}

Sera from 91 of the patients were tested for antibodies to Bacteroides species. Samples of venous blood $(10 \mathrm{ml})$ were taken from patients before appendicectomy and from those with septic complications when infection was detected clinically. After centrifugation and separation, sera were stored at $-70^{\circ} \mathrm{C}$ until required for testing. Blood was not collected from those convalescent patients who proved difficult to trace after hospital discharge. Antigens were prepared as described previously (Elhag and Tabaqchali, 1978) and the immune response was measured by the indirect-immunofluorescence technique described by Wulff and Lang (1975).

Serum from each patient was tested against the patient's own isolates and against 12 other antigenically distinct strains of Bacteroides - $B$. fragilis ( 6 strains), $\boldsymbol{B}$. ovatus (2), B. distasonis (2) and B. vulgatus (2)-with fluorescein-isothiocyanate conjugated with sheep antihuman IgG and goat anti-human IgM. Preparations were counterstained with Evans's Blue (George T. Gurr Ltd, London) $0.2 \% \mathrm{w} / \mathrm{v}$ in buffered physiological saline $(p \mathrm{H}$ 7.2) (PBS), mounted in glycerol $25 \% \mathrm{v} / \mathrm{v}$ in PBS. Fluorescence was read in an epifluorescence microscope (Opton, Feintechnik CmB, H D-7082 Oberkochen, West Germany).

Statistical analyses were made by the $\chi^{2}$ test.

\section{Results}

Of the 135 patients studied, 17 had normal appendices, 17 presented with phlegmonous appendicitis, 75 with gangrenous appendicitis and 26 with septic complications of appendicitis. The bacterial species isolated from appendices and appendixrelated infections are shown in table I. Anaerobes were more frequently isolated than aerobes and members of the $B$. fragilis group were predominant. The most common isolates among the aerobic bacteria were Escherichia coli and Klebsiella pneumoniae. There were no significant differences in the proportions of different genera found among the four patient groups.

Among the members of the $B$. fragilis group, the species $B$. fragilis was the one most commonly isolated followed by $B$. ovatus and $B$. distasonis (table II). There were no significant differences in the species of Bacteroides isolated from patients in groups 1,2 and $3 ; B$. fragilis, however, was isolated at a significantly higher relative frequency from patients in group $4(\mathrm{p}<0.01)$.

When the available sera from 91 of the patients were examined, antibodies against members of the

Table I. Bacterial species isolated from appendices of patients in different clinical groups

\begin{tabular}{ccccc}
$\begin{array}{c}\text { Number of isolations } \\
\text { * of stated } \\
\text { bacterial species from } \\
\text { patients in group } \dagger\end{array}$ \\
\hline 1 & 2 & 3 & 4 & All \\
$(17)$ & $(17)$ & $(75)$ & $(26)$ & $(135)$
\end{tabular}

\begin{tabular}{lrrrrr}
\hline Aerobes & & & & & \\
Escherichia coli & 11 & 11 & 53 & 10 & 85 \\
Klebsiella pneumoniae & 1 & 4 & 6 & 1 & 12 \\
Citrobacter freundi & 0 & 1 & 2 & 0 & 3 \\
Enterobacter cloacae & 0 & 0 & 2 & 0 & 2 \\
Proteus spp. & 0 & 2 & 3 & 0 & 5 \\
Pseudomonas spp. & 1 & 2 & 2 & 3 & 8 \\
Streptococcus spp. & 2 & 0 & 0 & 6 & 8 \\
Staphylococcus spp. & 0 & 2 & 2 & 0 & 4 \\
Anaerobes & & & & & \\
Bacteroides $¥$ spp. & 22 & 28 & 73 & 30 & 153 \\
Fusobacterium spp. & 1 & 0 & 0 & 0 & 1 \\
Veillonella spp. & 1 & 1 & 0 & 0 & 2 \\
Clostridium perfringens & 0 & 2 & 0 & 0 & 2 \\
Peptococcus spp. & 1 & 0 & 1 & 0 & 2 \\
Peptostreptococcus spp. & 0 & 0 & 0 & 2 & 2 \\
All species & 40 & 53 & 144 & 52 & 289 \\
& & & & &
\end{tabular}

\footnotetext{
* From appendix or infected, appendix-related site.

† Patient groups were: (1) normal; (2) phlegmonous; (3) gangrenous; (4) septic.

$\ddagger$ All species of Bacteroides.
} 
Table II. Bacteroides species isolated from appendices of patients in different clinical groups

\begin{tabular}{lccccc}
\hline & \multicolumn{5}{c}{$\begin{array}{c}\text { Number of isolations* of stated Bacteroides } \\
\text { species from patients in group } \dagger\end{array}$} \\
\cline { 2 - 6 } \multicolumn{1}{c}{ Species } & 1 & 2 & 3 & 4 & All \\
\hline B. fragilis & $(17)$ & $(17)$ & $(75)$ & $(26)$ & $(135)$ \\
B. ovatus & 7 & 11 & 28 & 22 & 68 \\
B. distasonis & 7 & 6 & 26 & 3 & 42 \\
B. vulgatus & 5 & 6 & 11 & 4 & 26 \\
B. thetaiotaomicron & 1 & 3 & 2 & 0 & 6 \\
B. uniformis & 2 & 0 & 2 & 1 & 5 \\
All species & 0 & 2 & 4 & 0 & 6 \\
\hline
\end{tabular}

* See footnote to table I.

$B$. fragilis group were detected in the sera of: 4 patients $(33 \%)$ in group $1 ; 6(54.5 \%)$ in group $2 ; 25$ $(59.5 \%)$ in group 3 ; and $24(92 \%)$ in group 4 (table III). The number of sera in which IgG or IgM antibodies (and their titres) against Bacteroides spp. were detected in the different patient groups is also shown in table III. There was no significant difference in bacteroides-antibody response among patients in groups 1,2 and 3 but the proportion of patients with bacteroides-antibodies in patient

Table III. Antibodies against Bacteroides species demonstrated in sera of patients from different clinical groups

\begin{tabular}{|c|c|c|c|c|c|c|}
\hline \multirow{3}{*}{$\begin{array}{l}\text { Patient } \\
\text { group }\end{array}$} & \multirow{3}{*}{$\begin{array}{c}\text { Number } \\
\text { of sera } \\
\text { tested }\end{array}$} & \multicolumn{5}{|c|}{$\begin{array}{l}\text { Number of sera with antibodies of } \\
\text { class and titre against Bacteroides spp. }\end{array}$} \\
\hline & & \multicolumn{2}{|c|}{ IgG } & \multicolumn{2}{|c|}{ IgM } & \multirow{2}{*}{$\begin{array}{c}\text { IgG or IgM } \\
\text { any titre } \\
\text { (total) }\end{array}$} \\
\hline & & $10-40$ & $80-160$ & $10-40$ & $80-160$ & \\
\hline (1) Normal & 12 & 2 & 2 & 1 & 0 & 4 \\
\hline (2) Phlegmonous & 11 & 2 & 4 & 0 & 0 & 6 \\
\hline (3) Gangrenous & 42 & 15 & 6 & 6 & 1 & 25 \\
\hline (4) Septic & 26 & 10 & 13 & 4 & 4 & 24 \\
\hline
\end{tabular}

Table IV. Antibodies against $B$. fragilis and other members of the $B$. fragilis group in sera of patients from different clinical groups

\begin{tabular}{|c|c|c|c|c|c|c|c|}
\hline \multirow{3}{*}{$\begin{array}{c}\text { Patient } \\
\text { group }\end{array}$} & \multirow{3}{*}{$\begin{array}{c}\text { Number } \\
\text { of sera } \\
\text { tested }\end{array}$} & \multicolumn{6}{|c|}{ Number of sera with antibodies against } \\
\hline & & \multicolumn{3}{|c|}{ B. fragilis } & \multicolumn{3}{|c|}{ other Bacteroides spp. } \\
\hline & & IgG & $\operatorname{lgM}$ & both $(\%)$ & $\operatorname{IgG}$ & IgM & both $(\%)$ \\
\hline (1) Normal & 12 & 3 & 1 & $3(25)$ & 2 & 0 & $2(17)$ \\
\hline (2) Phlegmonous & 11 & 4 & 0 & $4(27)$ & 5 & 0 & $5(45)$ \\
\hline (3) Gangrenous & 42 & 14 & 4 & $17(40 \cdot 5)$ & 13 & 3 & $16(38)$ \\
\hline (4) Septic & 26 & 23 & 8 & $24(92)$ & 8 & 0 & $8(31)$ \\
\hline
\end{tabular}


group 4 was significantly higher than that in the other groups $(p<0.01)$. There was no significant difference in the proportion of patients with bacteroides IgM-antibodies in groups 3 and 4.

The immune responses of the patients against $B$. fragilis and other organisms of the $B$. fragilis group are shown in table IV. There was no significant difference in $B$. fragilis - specific antibody response among patients in the patient groups $1-3$ but it was significantly more common in group $4(\mathrm{p}<0.01)$. However, the antibody response against other Bacteroides species was similar in all four groups. Among patients of group 4, IgM-antibody response was specific for $B$. fragilis among patients of group 3 , IgM antibodies were detected against various species of the $B$. fragilis group. The proportion of patients showing $B$. fragilis specific IgM antibodies was significantly higher in group 4 than in group 3 $(\mathrm{p}<0.05)$.

\section{Discussion}

In this study we investigated patients with acute appendicitis as well as patients with normal appendices and with septic complications of appendicitis. Both aerobic and anaerobic bacteria were isolated from all groups of patients, though in varied proportions. Anaerobic bacteria were more frequently encountered than facultative aerobes and organisms of the $B$. fragilis group were the predominant bacteria in all specimens, findings that are consistent with those of other workers (Leigh et al, 1974; Werner et al., 1975; Pieper et al., 1979 and 1982). Whereas the rate of isolation of $B$. fragilis from normal and inflamed appendices was similar, it was significantly higher in appendix-related infections and the association of $B$. fragilis with these infections is well documented (Andersen et al., 1972; Leigh et al., 1974; Willis et al., 1976). Although Pieper et al. (1979) investigated a smaller number of patients, including only two with normal appendices, their findings were generally similar to those reported here.

In the present study the rate of isolation of $B$. fragilis from appendices was higher than that reported from the colon in which that species accounts for only $0.5 \%$ of the microbial flora (Moore, 1977). Our results, however, were in agreement with those of Pieper et al. (1982) who studied the appendix microflora of 50 patients with acute appendicitis. The high isolation rate of $B$. fragilis from appendices and the demonstration of antibodies in the sera of their patients perhaps led these authors to conclude that $\boldsymbol{B}$. fragilis played a role in the pathogenesis of acute appendicitis. In their study, however, normal appendices were not examined.

The antibody titres in our series were generally low, probably resulting from the poor immunogenicity of the lipopolysaccharide of $B$. fragilis which has been shown to be biologically distinct from that of aerobic gram-negative bacteria (Kasper, 1976). In an earlier study (Elhag et al., 1977), antibody titres following extensive immunisation of rabbits with $B$. fragilis $\mathrm{O}$ antigen did not exceed 320 . Thus, because of the poor immunogenicity of these organisms it may be difficult to detect a significant rise in antibody titres in the sera of patients. This study has further shown that in normal individuals $B$. fragilis antibodies may be present in relatively high titre. Taking these factors into consideration, the demonstration of $B$. fragilis specific IgM antibodies in these patients may possibly be a more reliable index of current infection.

The antibody response to members of the $B$. fragilis group was similar among patients with normal and inflamed appendices, but significantly more common among those with septic complications. Pieper et al. (1982) reported rising titres of $B$. fragilis specific antibodies in patients with acute appendicitis and found that the immune response increased with the degree of organ destruction and duration of the inflammatory process. We have not, however, observed any correlation between the degree of inflammation and antibody titres.

We found no significant difference in the immune response among different patient groups to $B$. ovatus, $B$. distasonis and $B$. vulgatus, a finding similar to that of Pieper et al. (1979). Nevertheless, antibodies against $B$. fragilis itself were detected more often in patients with septic complications of appendicitis, and whereas these patients had IgM antibodies that were $B$. fragilis specific, others with acute appendicitis showed IgM-antibody response to a wide range of organisms of the $B$. fragilis group other than B. fragilis (i.e., B. ovatus, B. distasonis, B. vulgatus, $B$. uniformis and $B$. thetaiotaomicron) known to be dominant in the bowel but less frequently associated with infections (Moore, 1977; Polk and Kasper, 1977).

It seems from these findings that the antibody response to $B$. fragilis of patients with acute appendicitis is not due to infection by $B$. fragilis but to exposure of the appendix microflora to the immune system of the host, following necrosis of the appendix due to various factors such as obstruction. Different types of aerobic and anaerobic bacteria have been isolated from the surfaces of appendices and peritoneal cavities of patients with acute apendicitis (Leigh et al., 1974; Lari et al., 1976). From the 
above discussion, therefore, it may be concluded that $B$. fragilis does not play a significant role in the pathogenesis of acute appendicitis, but it is a major cause of the septic complications that may follow.

\section{REFERENCES}

Andersen B, Bendtsen A, Holbraad L, Schantz A 1972 Wound infections after appendicectomy. I. A controlled trial on the prophylactic efficacy of topical ampicillin in non-perforated appendicitis. II. A controlled trial on the prophylactic efficacy of delayed primary suture and topical ampicillin in perforated appendicitis. Acta Chirurgica Scandinavica 138:531-536.

Burkitt D P 1971 The aetiology of appendicitis. British Journal of Surgery 58:695-699.

Elhag K M, Bettelheim K A, Tabaqchali S 1977 Serological studies of Bacteroides fragilis. Journal of Hygiene 79:233241 .

Elhag K M, Tabaqchali S 1978 A study of the surface and somatic antigens of Bacteroides fragilis. Journal of Hygiene 80:439-449.

Holdeman L V, Cato E P, Moore W E C (ed) 1977 Anaerobe laboratory manual, 4th edn. Virginia Polytechnic Institute and State University, Blacksburg, Virginia.

Isenberg $\mathrm{H} \mathrm{D}$, Washington J A, Balows A, Sonnenwirth A C 1980 Collection handling and processing of specimens. In: Lenette EH et al, (eds) Manual of clinical microbiology, 3rd edn. American Society for Microbiology, Washington DC $p$ 52.

Kasper D L 1976 Chemical and biological characterization of lipopolysaccharide of Bacteroides fragilis subspecies fragilis. Journal of Infectious Diseases 134:59-66.

Lari J, Kirk D, Howden R 1976 Bacteriological survey of acute appendicitis in children. British Journal of Surgery 63:643646.

Leigh D A, Simmons K, Norman E 1974 Bacterial flora of the
This study was supported by Kuwait University Research Council (grant no. MI 007). We wish to thank Mrs R. Chandy and Mrs A. Abraham for technical assistance and Mr I. Sulko for statistical analyses.

appendix fossa in appendicitis and postoperative wound infection. Journal of Clinical Pathology 27:997-1000.

Moore W E C 1977 Anerobes as normal flora: gastrointestinal tract. In: Finegold S M (ed) Metronidazole: Proceedings of the International Metronidazole Conference. (Excerpta Medica International Congress Series No. 438) Excerpta Medica, Amsterdam p 222.

Pieper R, Kager L, Lindberg A A, Nord C E 1979 Acute appendicitis and Bacteroides fragilis. Scandinavian Journal of Infectious Diseases. Supplement 19:92-97.

Pieper R, Kagar L, Weintraub A, Lindberg A A, Nord C E 1982 The role of Bacteroides fragilis in the pathogenesis of acute appendicitis. Acta Chirurgica Scandinavica 148:39-44.

Polk B F, Kasper D L 1977 Bacteroides fragilis subspecies in clinical isolates. Annals of Internal Medicine 86:569-571.

Shackelford R T, Zuidema G D (eds) 1981 Surgery of the alimentary tract, 2nd edn. vol. 3. W B Sanders Company, Philadelphia, p 57.

Veillon M H, Zuber H 1898 Recherches sur quelques microbes strictement anaérobies et leur rôle en pathologie. Archives de Medicine Experimentale et d'Anatomie Pathologique 10:517-545.

Werner H, Kunstek-Santos H, Schockemohle C, Gundurewa M 1975. Bacteroides und appendizitis. Pathologia et Microbiologia 42:110-118.

Willis A T et al, 1976 Metronidazole in prevention and treatment of bacteroides infections after appendicectomy. British Medical Journal 1:318-321.

Wulf H, Lange J V 1975 Indirect immunofluorescence for the diagnosis of Lassa fever infection. Bulletion of the World Health Organization 52:429-436. 